\title{
Radiation Exposure from Nuclear Power Plants in Korea: 2011-2015
}

\author{
Young Khi Lim \\ Department of Radiology, Gachon University, Incheon, Korea
}

\section{Technical Paper}

Received October 11, 2017

Revision November 4, 2017

Accepted November 7, 2017

Corresponding author: Young Khi Lim

Department of Radiology, Gachon

University, 191 Hambangmoe-ro,

Yeonsu-gu, Incheon 21936, Korea

Tel: +82-32-820-4365

Fax: +82-32-820-4365

E-mail:yklim@gachon.ac.kr

This is an Open-Access article distributed under the terms of the Creative Commons Attribution NonCommercial License (http://creativecommons.org/ licenses/by-nc/4.0) which permits unrestricted noncommercial use, distribution, and reproduction in any medium, provided the original work is properly cited.

Copyright $\odot$ 2017The Korean Association for Radiation Protection

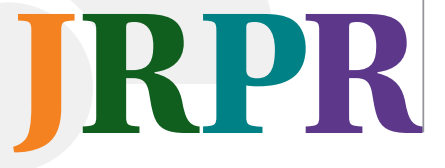

Background: On June 18, 2017, Korea's first commercial nuclear reactor, the Kori Nuclear Power Plant No. 1, was permanently suspended, and the capacity of nuclear power generation facilities will be adjusted according to the governments denuclearization policy. In these circumstances, it is necessary to assess the quality of radiation safety management in nuclear power plants in Korea by evaluating the radiation dose associated with them.

Materials and Methods: The average annual radiation dose per unit, the annual radiation dose per person, and the annual dose distribution were analyzed using the radiation dose database of nuclear reactors for the last 5 years. The results of our analysis were compared to the specifications of the Nuclear Safety Act and Medical Law in Korea.

Results and Discussion: The annual average per unit radiation dose of global major nuclear power generation was 720 man-mSv, while that of Koreas nuclear power plants was 374 man$\mathrm{mSv}$. No workers exceeded $50 \mathrm{mSv}$ per year or $100 \mathrm{mSv}$ in 5 years. The individual radiation dose according to occupational exposure was $0.59 \mathrm{mSv}$ for nuclear workers, $1.77 \mathrm{mSv}$ for nondestructive workers, and $0.8 \mathrm{mSv}$ for diagnostic radiologists.

Conclusion: The radiation safety management of nuclear power plants in Korea has achieved the best outcomes worldwide, which is considered to be the result of the as-low-as-reasonablyachievable (ALARA) approach and strict radiation safety management. Moreover, the occupational exposures were also very low.

Keywords: Nuclear power plant, Exposure dose, Radiation worker, Dose distribution, Dose limit

\section{Introduction}

The South Korean government's denuclearization policy has led to the permanent shutdown of the nation's first commercial nuclear reactor, Kori Nuclear Power Plant No. 1 , on June 18,2017 , as well as the inevitable scale-down of future nuclear power generation capacities. The construction of the Shin-Kori No. 5 and 6 nuclear reactors has only been resumed lately following a decision made by a dedicated public debate commission, after being suspended for a long time. This attempt to overhaul the country's power generation scheme has undermined the nation's prospects of exporting its advanced nuclear technologies, ceding space in this market to China and Russia.

Globally, a total of 448 nuclear power plants are being operated as of September 2017, with an additional 57 under construction, 19 of which are in China and 2 in Japan. South Korea is the sixth largest nuclear power generator in the world [1]. Nuclear 
power plants supplied 161,995 GWh or $30.64 \%$ of all electricity generated nationwide in 2016, a significant increase from 2,324 GWh or $7.4 \%$ in 1978 , when the country first introduced nuclear power. As of the end of 2016, a total of 24 reactors are currently in operation (not including the suspended Kori Nuclear Power Plant No. 1); 20 of them are pressurized water reactors (PWR) and 4 are pressurized heavy-water reactors (PHWR). The PHWRs Wolsong 1 through 4 are all located in the Wolsong Nuclear Power Plant complex, while an PWR (Shin-Wolsong No. 1) has been recently added.

Amid the series of changes in nuclear power policy-the suspension of Kori Nuclear Power Plant No. 1, the ban on extended operation after reaching a plant's design life, and the cancellation of new plant construction-it is timely to assess and discuss the level of radiation safety management in terms of radiation exposure. The radiation dose database of nuclear reactors should be studied on a regular basis to alleviate public anxiety about nuclear power plants and to prepare for the future shutdown of old facilities. In this regard, this study evaluated the quality of South Korea's radiation safety management by analyzing 5-year radiation exposure data from nuclear power plants and comparing them to trends in other groups of radiation workers and other nuclear nations throughout the world.

\section{Materials and Methods}

\section{Subjects and radiation exposure data}

Registered radiation workers over the 5 -year period between 2011 and 2015 were selected as subjects. Radiation exposure data for nuclear workers, including the work classification, were collected with the cooperation of Korea Hydro \& Nuclear Power (KHNP). Nuclear safety yearbooks published by the Nuclear Safety and Security Commission were chosen as the data source for radiation workers in other fields regulated under the Nuclear Safety Act. Annual reports on occupational radiation exposure in diagnostic radiology by the Korea Centers for Disease Control and Prevention were utilized as the source of data for radiation workers under Medical Law.

Radiation work was classified with reference to the KHNP data. Subjects were categorized as employees of KHNP, the operator of nuclear reactors; KPS, the maintenance and repair service provider; and others, including employees of radiation safety management and equipment maintenance service providers. Some of the workers were employed by 2 or more facilities, which was adjusted for to avoid redundancy.

Radiation exposure was analyzed according to each unit's annual average, operational status, and reactor type, by comparing the radiation dose distribution during normal operation and planned outages, as well as between PWRs and PHWRs. The 5-year trend of collective doses for all nuclear workers and the per unit annual average were also studied. Internal and external exposure were compared. Individual annual radiation exposure distribution was analyzed for 7 intervals (under 0.1 mSv, 0.1-1 mSv, 1-10 mSv, 10-20 mSv, 20$30 \mathrm{mSv}, 30-50 \mathrm{mSv}$, and $50 \mathrm{mSv}$ or higher), and cases of excessive exposure were dealt with according to the standards of the Nuclear Safety Act.

The average radiation exposure of nuclear power plant workers according to nuclear safety yearbooks provided by the Nuclear Safety and Security Commission was compared to that of medical radiation workers determined using the registry of the Korea Centers for Disease Control and Prevention. Radiation exposure by occupation, the distribution of exposure by dose, and the amount of those who exceeded the dose limit were evaluated to assess the quality of radiation safety management in nuclear power plants.

The average per unit doses of South Korean nuclear power plants were compared to those of other major nuclear power generators worldwide, using the World Association of Nucle-

Table 1. Classification of Types of Radiation Work

\begin{tabular}{ll} 
Working code & \\
\hline A & Refueling \\
B & Reactor vessel or internal \\
C & S/G primary side \\
D & S/G secondary side \\
E & RHR and Sl system \\
F & CVCS and coolant pump seal water system \\
G & Pressurizer \\
H & Reactor water clean-up system \\
I & RCS pump \\
J & Primary circuit \\
K & Valve work \\
L & Routine inspections \\
M & General work \\
N & Scaffolding \\
O & Insulation \\
P & Control rod drive \\
Q & Dose by system listed above \\
R, S, T & Special work \\
\hline
\end{tabular}

S/G, steam generator; RHR, residual heat removal; SI, safety injection; CVCS, chemical volume control system; RCS, reactor coolant system. 
ar Operators Performance Indicator (WANO PI) database.

\section{Radiation exposure by type of work}

Radiation work at nuclear power plants is broadly classified into 20 categories, shown in Table 1, for both PWRs and PHWRs. Radiation exposure levels were analyzed for each type of work based on the KHNP data. Exposure levels for a more detailed classification of around 200 items have been studied, but will not be disclosed here for reasons of confidentiality. The broader classification of radiation work was consistent for both PWRs and PHWRs, while the characteristics and special features of each reactor type were taken into account in the more detailed analysis.

Dose distribution by operational status was studied for normal operation and planned outage periods, with the latter referring to planned maintenance and repair in cases of regular fuel change, the end of equipment life, or defects in the main equipment. The operational status was occasionally divided into 3 groups, in cases when interim maintenance was performed upon the detection of abnormal defects outside of planned outages. The International Atomic Energy Agency Power Reactor Information System (IAEA PRIS) database was used for unplanned outages, an immediate indicator of the safe operation of nuclear power plants.

\section{Results and Discussion}

\section{Distribution of radiation workers}

Table 2 lists the number of registered radiation workers in South Korea. As of December 2015, 14,926 workers were registered as working at 24 operating nuclear power plants, 140 more than the figure of 14,786 in December 2013.

Only 235 workers were added to the population of 14,691 radiation workers in 2011, making the total 14,926 in 2015, although 3 new plants came into operation over the same

Table 2. Number of Operating Nuclear Power Plants and Radiation Workers in the Republic of Korea

\begin{tabular}{lcc}
\hline Year & $\begin{array}{c}\text { Number of operating } \\
\text { nuclear power plants }\end{array}$ & Number of radiation workers \\
\hline 2011 & 21 & 14,691 \\
2012 & 23 & 14,715 \\
2013 & 23 & 14,786 \\
2014 & 23 & 14,260 \\
2015 & 24 & 14,926 \\
\hline
\end{tabular}

period. The dip in 2014 was likely caused by the reduced duration of planned outages ( 850 days less than the previous year), and continued efforts to cut down radiation.

\section{Radiation exposure dose distribution for nuclear workers}

We found that the external exposure dose of nuclear workers was measured monthly using thermoluminescent dosimeters allocated to each individual. Two dosimeters were used to measure the effective dose for jobs where the dose rate on the body parts that directly come in contact with radiation was $30 \%$ or higher, or performed in high-radiation areas with an hourly dose rate of $1 \mathrm{mSv}$ or higher and exposure to more than $2 \mathrm{mSv}$ at a time.

For internal exposure, the committed effective dose was measured using both a whole body counter [2] as a direct method and a liquid scintillation counter, an indirect method of testing urine samples [3].

According to the WANO PI and the corresponding graph in Figure 1, South Korea had the lowest annual per unit collective exposure in 2015 at 374 man-mSv, just $52 \%$ of the worldwide average of 720 man-mSv. The global annual average per unit exposure stood at 852 man-mSv, 758 man-mSv, 725 man-mSv, 730 man-mSv, and 720 man-mSv each year between 2011 and 2015, compared to Korea's 532 man-mSv, 455 man-mSv, 527 man-mSv, 360 man-mSv, and 374 man$\mathrm{mSv}$, respectively. ${ }^{1)}$ This is a clear demonstration of Korea's exceptional radiation safety management performance, given that the WANO PI is one of the most reliable and objective criteria used worldwide. The indicator is a tally of the total radiation dose that workers are exposed to in all types of reactors. These findings serve as evidence of systematic radiation safety management as a component of the comprehen-

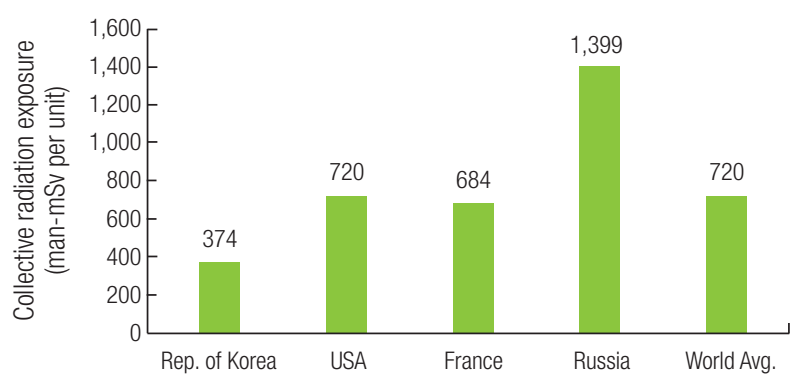

Fig. 1. Worldwide collective radiation exposure in 2015 (man-mSv/ unit).2)

1) World Association of Nuclear Operators (WANO) Performance Indicators 2015, 2016

2) 2016 World Association of Nuclear Operators Performance Indicator. 
sive radiation reduction projects carried out by KHNP, which runs nuclear reactor operation projects [4].

By reactor type, radiation exposure at PWRs was dominant during planned outages over the 5 -year periods leading up to 2013 and to 2015 , accounting for $91.3 \%$ and $89.7 \%$ of the exposure, respectively. In contrast, radiation exposure at PHWRs during planned outages dropped by $10 \%$, to $74.1 \%$, from $85.1 \%$ over the 5 -year period ending in 2015 , possibly due to the high dose of radiation released during the pressure tube replacement work at Wolsong No. 1 between 2009 and 2010. PHWRs tend to release a higher dose of radiation during normal operation, including fuel and/or fuel handling machine replacements, than PWRs [5]. PHWRs in Korea seem to be safely managed, since the radiation exposure during normal operation generally accounted for $20 \%$ of all exposure.

The annual collective radiation exposure in 2013 shown as Table 3 was 12,122 man-mSv, up by 1,650 man-mSv from the year before, not because of unusually high amounts of radiation work, but due to extended planned outage periods ( $70 \%$ longer than 2012), as well as aged plants, comprehensive equipment upgrades, and preemptive inspections.

In contrast, the annual collective radiation exposure in 2014 was 8,325 man-mSv, down by 3,797 man-mSv (31\%)

Table 3. Annual Collective Radiation Exposure, According to Operational Mode and Reactor Type

\begin{tabular}{llrrrr}
\hline & & \multicolumn{3}{c}{ Collective radiation exposure (man-mSv) } \\
\cline { 3 - 6 } & & $\begin{array}{c}\text { Normal } \\
\text { operation }\end{array}$ & O/H & $\begin{array}{c}\text { Unexpected } \\
\text { maintenance }\end{array}$ & Total \\
\hline 2011 & PWR & 567 & 8,526 & 9 & 9,102 \\
& PHWR & 615 & 1,457 & 0 & 2,072 \\
& Total & 1,182 & 9,983 & 9 & 11,174 \\
2012 & PWR & 675 & 7,240 & 5 & 7,920 \\
& PHWR & 605 & 1,793 & 154 & 2,552 \\
& Total & 1,280 & 9,033 & 159 & 10,472 \\
2013 & PWR & 1,004 & 8,828 & 327 & 10,159 \\
& PHWR & 298 & 1,500 & 164 & 1,962 \\
& Total & 1,302 & 10,328 & 492 & 12,122 \\
2014 & PWR & 855 & 5,970 & 1 & 6,826 \\
& PHWR & 276 & 1,165 & 58 & 1,499 \\
& Total & 1,131 & 7,135 & 59 & 8,325 \\
2015 & PWR & 748 & 6,323 & 65 & 7,136 \\
& PHWR & 361 & 1,353 & 11 & 1,725 \\
Total & 1,110 & 7,676 & 75 & 8,861 \\
Avg. & PWR & 770 & 7,377 & 81 & 8,228 \\
& PHWR & 431 & 1,454 & 77 & 1,962 \\
Total & 1,201 & 8,831 & 158 & 10,190 \\
\hline
\end{tabular}

PWR, pressurized water reactor; PHWR, pressurized heavy-water reactor; $\mathrm{O} / \mathrm{H}$, overhaul. from 2013, thanks to a reduction in planned outages by 850 days (44.6\%). In 2015, the amount increased by 537.05 man$\mathrm{mSv}(6.45 \%)$ from the previous year to 8,861 man-mSv, with $4.1 \%$ longer planned outage periods.

It can be seen that the variation of annual collective radiation exposure in nuclear power plants was primarily determined by the duration of planned outage periods, which is evidence of Korea's stable radiation safety management capability that allows for fluctuation only through planning.

Radiation exposure by work type was found to be associated with replacement projects for major equipment such as steam generators or deterioration of equipment. The types of work that generated the most radiation in PWRs included the disassembling and assembling of reactors during planned outages, eddy current testing (ECT) of steam generator tubes, work related to nuclear instrumentation systems, coolant pumps, and radiation safety management. The types of work with the highest radiation exposure in PHWRs were the replacement of nuclear fuels, fuel handling machine maintenance, ECT of steam generator tubes, and work on steam generator tubes, delayed neutron monitoring system tubing, and radiation safety management. There was no major difference in the types of work that released the highest radiation dose between reactor types, other than fuel replacement procedures performed during normal operation in the case of PHWRs. In terms of operational status, $87 \%$ of all exposure took place during planned outages in 2015, as seen in Figure 2. The percentage was higher at $88.6 \%$ for PWRs, compared to $78.4 \%$ for PHWRs. PHWRs generated more radiation during normal operation than their counterparts due to fuel replacement.

\section{Radiation exposure type}

Radiation exposure can be external or internal to the body, depending on the source of radiation. On average, external

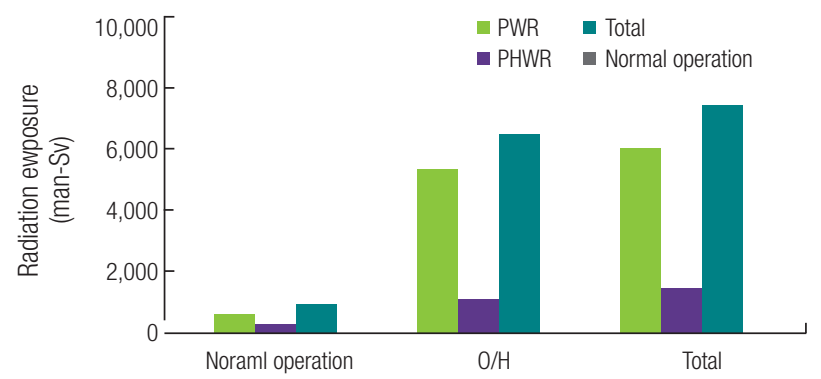

Fig. 2. Comparison of radiation exposure between normal operation and $\mathrm{O} / \mathrm{H}$ periods. 
Table 4. Annual Collective Radiation Exposure: External Exposure Versus Internal Exposure (man-mSv)

\begin{tabular}{lrcr}
\hline & External exposure & Internal exposure & \multicolumn{1}{c}{ Total } \\
\hline 2011 & $10,730(1,631)$ & $443(441)$ & 11,173 \\
2012 & $9,934(2,014)$ & $537(536)$ & 10,471 \\
2013 & $11,615(1,455)$ & $507(506)$ & 12,122 \\
2014 & $7,972(1,148)$ & $352(351)$ & 8,324 \\
2015 & $8,555(1,421)$ & $307(305)$ & 8,862 \\
Average & $9,761(1,533)$ & $429(428)$ & 10,190 \\
\hline
\end{tabular}

( ): annual radiation exposure in heavy-water plants.

exposure accounted for $95.8 \%$ of exposure over the 20112015 period, and internal exposure for $4.2 \%$, maintaining a trend similar to that observed in $2009-2013$ (5.5\% versus 4.5\%) shown as Table 4. Internal exposure mostly took place in PHWRs, which accounted for 427 of the average of 429 man-mSv. In PHWRs, most internal radiation exposure is attributed to tritium, which is used as a moderator [6].

Internal exposure made up an average of $12.8 \%$ of total radiation exposure in Korean PHWRs over the 2009-2013 period, while the share went up to $21.8 \%$ for the $2011-2015$ period. This $9 \%$ gap is explained by the pressure tube replacement project conducted in 2009 and 2010 for Wolsong, which ramped up external exposure at the plant significantly by $60-70 \%$, rather than an increase of internal exposure in PHWRs between 2011 and 2015. No unusual high-radiation work was reported at the time of this study.

Internal radiation exposure at PHWRs maintained a similar share during 2011-2015, at 21.8\%, and 2011-2013, at 22\%, after the pressure tube replacement. This means that currently no unusual high-radiation work is done in PHWRs [5].

\section{Annual individual radiation exposure of radiation workers}

During 2011-2015, 83.5\% of all radiation workers were exposed to less than the public dose limit of $1 \mathrm{mSv}$, and none of them exceeded the $50 \mathrm{mSv}$ annual dose limit. In 2009 and 2010, respectively, 47 and 39 workers were exposed to 20-30 $\mathrm{mSv}$ of radiation as part of the Wolsong No. 1 pressure tube replacement. At the same time, only 1 worker exceeded the $20 \mathrm{mSv}$ threshold by being exposed to $26.6 \mathrm{mSv}$ of radiation while performing insulator replacement during the Kori No. 3 planned outage in 2012. There has been no case of exceeding the management dose of $30 \mathrm{mSv}$ ( $60 \%$ of the $50 \mathrm{mSv}$ annual dose limit) over the decade leading up to 2015.

As for radiation workers in other sectors, the average individual exposure for the 43,078 radiation workers listed in the
Korea Foundation of Nuclear Safety registry in 2015 was 0.6 $\mathrm{mSv}$, close to the $0.59 \mathrm{mSv}$ of nuclear workers. The occupations in that registry include most engineering fields, doctors, nurses, and radiologists within the fields of diagnostic nuclear medicine and radiation oncology. The 2016 Nuclear Safety and Security Commission's yearbook reported that the average exposure of 7,645 non-destructive workers was $1.77 \mathrm{mSv}$, $75 \%$ of the 2014 data.

The annual average dose of non-destructive workers between 2011 and 2015 stood at $2.39 \mathrm{mSv}, 3.43 \mathrm{mSv}, 3.87 \mathrm{mSv}$, $2.37 \mathrm{mSv}$, and $1.77 \mathrm{mSv}$ each year, demonstrating a decreasing trend. However, this group had the highest 5-year average annual dose at $2.77 \mathrm{mSv}$, compared to other occupational groups. They were exposed to more than twice the radiation than radiologists, the most vulnerable class within the diagnostic nuclear medicine field, with 5-year average of 0.95 mSv.

Meanwhile, radiation workers are also separately defined and managed by the Medical Law of Korea. The 2015 individual exposure data of medical radiation workers under medical law showed that the number of radiation-generating diagnostic devices increased by $3.4 \%$ from the previous year, from 75,762 to 78,347 . In 2015 , there were 76,493 medical radiation workers, including doctors, dentists, and radiologists in charge of the safe management of diagnostic radiation devices, up by $7.6 \%$ from 2014 and by a whopping $27 \%$ from 60,430 in 2011. In fact, there were 33,415 more radiation workers under medical law than the 43,078 registered under the Nuclear Safety Act. Radiation workers in the medical sector largely consist of doctors, dentists, radiologists, and nurses in the field of diagnostic medicine. Their average annual individual radiation exposure was $0.39 \mathrm{mSv}$, and radiologists were the most vulnerable group, exposed to an annual average of $0.95 \mathrm{mSv}$ radiation, which corresponded to annual values of $1.16 \mathrm{mSv}, 1.01 \mathrm{mSv}, 0.94 \mathrm{mSv}, 0.85 \mathrm{mSv}$, and $0.8 \mathrm{mSv}$ from 2011 to 2015, respectively.

When compared to the annual permissible dose limits, 28 nuclear workers exceeded the limit, out of a total of 209,482 person-years between 2011 and 2015, 500\% more than the 9 medical radiation workers who did so out of a total of 336,886 person-years over the same period. However, simply looking at the numbers can be misleading in terms of evaluating the overall level of safety. Rather, we concluded that radiation safety management is under good control in Korea, given the downward trend of individual doses in both the medical and nuclear groups, with the exception of non-destructive work- 
Table 5. Radiation Exposure Distribution among Radiation Workers in Korean Nuclear Power Plants

\begin{tabular}{|c|c|c|c|c|c|c|c|c|c|}
\hline \multirow{2}{*}{ Year } & \multicolumn{9}{|c|}{ Radiation exposure (mSv) } \\
\hline & $<0.1$ & $0.1-1$ & $1-10$ & $10-15$ & $15-20$ & $20-30$ & $30-50$ & $>50$ & Total \\
\hline 2011 & 9,069 & 2,908 & 2,554 & 147 & 13 & 0 & 0 & 0 & 14,691 \\
\hline 2012 & 9,436 & 2,715 & 2,420 & 131 & 12 & 1 & 0 & 0 & 14,715 \\
\hline 2013 & 9,321 & 2,892 & 2,325 & 224 & 24 & 0 & 0 & 0 & 14,786 \\
\hline 2014 & 9,811 & 2,382 & 1,985 & 77 & 5 & 0 & 0 & 0 & 14,260 \\
\hline 2015 & 10,129 & 2,615 & 2,079 & 95 & 8 & 0 & 0 & 0 & 14,926 \\
\hline Total & $\begin{array}{l}47,766 \\
(65.1 \%)\end{array}$ & $\begin{array}{c}13,512 \\
(18.4 \%)\end{array}$ & $\begin{array}{r}11,363 \\
(15.5 \%)\end{array}$ & $\begin{array}{c}674 \\
(0.9 \%)\end{array}$ & $\begin{array}{c}62 \\
(0.08 \%)\end{array}$ & $\begin{array}{c}1 \\
(0.001 \%)\end{array}$ & 0 & 0 & 73,378 \\
\hline
\end{tabular}

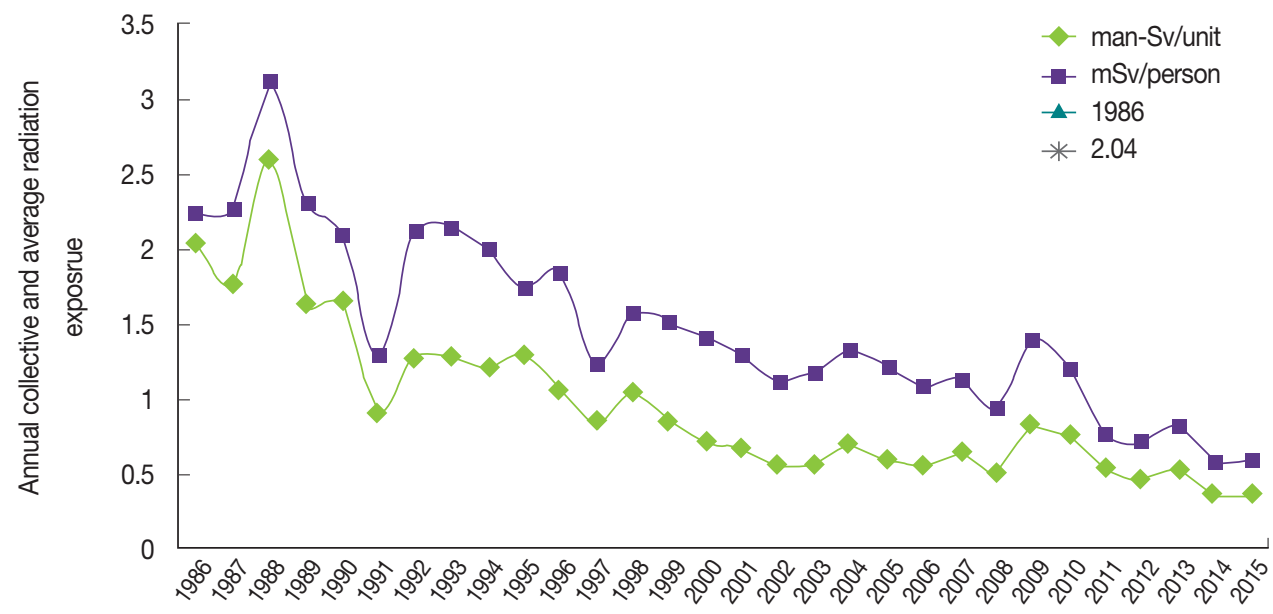

Fig. 3. Trend in the annual collective radiation exposure per reactor unit and average radiation exposure for radiation workers in Korean nuclear power plants.

ers.

During the 2011-2015 period, 99.999\% of Korean nuclear workers were exposed to less than $20 \mathrm{mSv}$ of radiation, with the exception of 1 case in 2012 in which the $20 \mathrm{mSv}$ threshold was exceeded shown as Table 5. Additionally, 334 of all 336,886 medical radiation workers were reported to have exceeded the limit. This is merely $0.1 \%$ of all medical radiation workers, while the portion was even smaller for nuclear workers at $0.001 \%$, corresponding to 1 out of 73,378 workers.

These results suggest an important finding: medical radiation workers generally work with lower-dose devices and are thus exposed to a smaller annual average dose (0.39 mSv) than nuclear workers ( $0.59 \mathrm{mSv})$ in 2015 , but at the same time a higher percentage of medical workers exceeded the $20 \mathrm{mSv}$ limit. In other words, nuclear power plants are doing an outstanding job in radiation safety management in comparison to other fields.

Next, we analyzed the per unit radiation dose over the past 20 years. As shown in Figure 3, per unit radiation exposure dropped notably from 2.6 man-Sv in 1988 to 0.35 man-Sv in
2015, while the annual average individual exposure fell from $3.13 \mathrm{mSv}$ to $0.59 \mathrm{mSv}$ over the same period. This was thanks to the efforts to reduce radiation starting in the design phase of power plants with the as low as reasonably achievable (ALARA) initiative and follow-up checklists [7], as well as other comprehensive radiation protection policies put in place by KHNP, such as mid- to long-term radiation reduction plans and lead vest dose reduction effect analysis [8].

Korean nuclear power plants have managed to limit cases of excessive exposure to 1 in the most recent 5-year period, even though high-radiation tasks are inevitable during steam generator and reactor coolant maintenance jobs during planned outages. Furthermore, the 2015 IAEA PRIS report listed Korea's unplanned outage rate as the lowest at 0.13 cases per unit, compared to 0.8 in the USA, 2.67 in France, and 1.07 in the UK.

Many different standards can be applied to assess the quality of radiation safety management in nuclear power plants, but some of the most basic and simple standards include average annual individual exposure dose and distribu- 
tion, annual dose limit, and the annual management dose limit of $20 \mathrm{mSv}$. South Korea has been shown to have a better radiation safety management system than its global counterparts by various means.

Nuclear power plants supply approximately $30 \%$ of all electricity in South Korea as of 2015, serving as one of the key industries that support the nation. Amid the government's directive to reduce the nation's nuclear dependency, it is imperative to precisely diagnose and understand the current status of nuclear power plants. To this end, the radiation exposure status of nuclear power plants must be assessed on a regular basis and ways to improve any issues must be identified.

\section{Conclusion}

South Korea's nuclear power plants are operated under rigid safety control that outperforms all other countries, as evidenced by the global nuclear power plant operation data issued by the IAEA. Moreover, Korea had by far the lowest unplanned outage rate, a major indicator of safe operation, at 0.13 cases per unit, beating the value of 0.8 of the US, the second safest nuclear power plant operator in the world.

There was no case of exceeding the annual dose limit or even $30 \mathrm{mSv}$ ( $60 \%$ of the annual limit) over the last 10 years, thanks to incessant efforts to improve the safety management of nuclear power plants and to reduce radiation.

Although these results and achievements mean a lot, it is best to keep in mind that unexpected abnormalities are bound to happen. A more systematic radiation protection system and radiation reduction efforts are required [9]. Radiation safety management becomes especially important in case of the shutdown of reactors following the government's denuclearization policy. This should include setting up a more detailed database of radiation safety management, as well as a regular assessment process.

\section{References}

1. International Atomic Energy Agency. Nuclear Power Reactors in the world reference data; Series No. 2. IAEA-RDS-2/36. 2016;1011.

2. Kim JI, Lee BI. Application of the detection of external contamination on radiation workers for bed type whole body counting using Monte Carlo method. J. Radiat. Prot. Res. 2013;38(4):242245.

3. Kim HG, Kong TY, Jeong WT, Kim ST. An international tritium concentration analysis in urine sample as a function of submission time intake at Korean pressurized heavy water reactors. J. Radiat. Prot. Res. 2009;34(4):184-189.

4. Kim SK, Shin SW, Lim BC. Long-term radiation dose reduction plan of KHNP. J. Radiat. Prot. Res. 2003;28(2):137-143.

5. Lim YK. Radiation exposure on radiation workers of nuclear power plants in Korea: 2009-2013. J. Radiat. Prot. Res. 2015;40 (3):162-167.

6. Kim HG, Kong TY. Analysis of metabolism and effective half-life for tritium intake of radiation workers at pressurized heavy water reactor. J. Radiat. Prot. Res. 2009;34(2):87-94.

7. Song YI, Kim HJ, Park HK, Kim HG. The optimization experience of occupational exposure during unclear power plant outage. J. Radiat. Prot. Res. 2003;28(2):145-154.

8. Kim JI, Lee BI, Lim YK. Analysis of a lead vest dose reduction effect for the radiation field at major working places during refueling outage of Korean PWR nuclear power plants. J. Radiat. Prot. Res. 2013;38(4):237-241.

9. Lee BI, Kim SI, Suh DH, Jin YW, Kim JI, Choi H, Lim YK. Radiation dose distribution for workers in South Korean nuclear power plants. Radiat. Prot. Dosim. 2010;140(2):202-206. 